\title{
Supplementary feeding effects on multiple fixed-ratio performance of rhesus monkeys
}

\author{
TIMOTHY F. ELSMORE \\ Walter Reed Army Institute of Research, Washington, D.C. 20012
}

\begin{abstract}
Monkeys were maintained on a four-component multiple fixed-ratio (FR) schedule of reinforcement in which FRs of $1,20,60$, or 180 were in effect in the presence of different colored lights. In each session a maximum of eight food pellets could be earned, and a session began every $2 \mathrm{~h}$ around the clock. Supplementary food pellets were given at the same time each morning. As the number of supplementary pellets was increased from 0 to 180 , fewer pellets were earned, and longer latencies to the onset of responding each component occurred. In all cases effects were greatest on components requiring the most responding for food presentation.
\end{abstract}

Numerous experiments have investigated effects of food deprivation upon performance under multiple schedules of food presentation (Ferster \& Skinner, 1957). Most of these have involved two-component schedules in which one component was extinction and the other, variable interval (e.g., Dinsmoor, 1952; Hegge, 1966; Powell, 1971, 1973). These studies showed either no systematic effects of deprivation upon discriminative responding or a greater proportional effect on responding in the extinction portion of the schedule. Few investigators have examined deprivation effects in multiple schedules where reinforcement was available in more than one component. Gollub and Urban (1958) examined effects of changes in body weight on performance under a multiple variableinterval schedule with different mean interval values in the two components. They found no systematically different effects in the two components, although a large difference emerged when both components were changed to extinction. Carlton (1961) examined a number of multiple schedules in which continuous reinforcement (CRF) was alternated with different intermittent reinforcement schedules. In all cases deprivation changes had a greater effect on behavior during the intermittently reinforced component.

These results all suggest that relative response rates within multiple schedules do not necessarily remain constant when the organism is challenged by variables generally thought to weaken behavior. Nevin (1974, Note 1) notes that deprivation effects on multipleschedule performance resemble the effects of other variables that modulate response rate, including extinc-

Reprints may be obtained from the author, Department of Medical Neurosciences, Walter Reed Army Institute of Research, Washington, D.C. 20012. In conducting the research described in this report, the investigators adhered to the "Guide for Laboratory Animal Facilities and Care," as promulgated by the Committee of the Guide for Laboratory Animal Facilities and Care of the Institute of Laboratory Animal Resources, National Academy of Sciences, National Research Council. tion, punishment, and reinforcement for alternative behaviors. In all cases, the effects are greater in the schedule components associated with the least favorable conditions of reinforcement. While the bulk of the research reviewed by Nevin was concerned with interval schedules of reinforcement, the present experiment examines the effects of supplementary feeding on performance of monkeys under a four-component multiple schedule of food presentation with different fixed ratios (FRs) in each component. Sessions were run on alternate hours throughout the day to assess the time course of the effects of prefeeding.

\section{METHOD}

\section{Subjects}

Two male rhesus monkeys, Pete and Max, each weighing about $6 \mathrm{~kg}$, served as subjects. Pete had served in a previous experiment involving continuous and random interval schedules of food reinforcement. Max was experimentally naive. The animals received about $100 \mathrm{~g}$ of fruit each day and had free access to water. Each received his entire ration of food pellets under the experimental procedure.

\section{Apparatus}

The subjects were separately housed in combined livingexperimental cages. A stainless steel lever was mounted at a height of $30 \mathrm{~cm}$ on one wall of each cage. The lever protruded into the cage about $4 \mathrm{~cm}$, was $1 \mathrm{~cm}$ wide, and required a force of about $.4 \mathrm{~N}$ through a distance of $1 \mathrm{~cm}$ to operate. An in-line display unit was mounted $6 \mathrm{~cm}$ above the lever and could be illuminated in white, yellow, blue, or red. Food pellets (Noyes $.75 \mathrm{~g}$ ) were delivered into an opening $18 \mathrm{~cm}$ to the left and $12 \mathrm{~cm}$ below the lever. Each cage was contained in a soundattenuating booth that also contained a speaker for providing masking noise. Solid state programming apparatus and a papertape reader were used to program experimental contingencies, and data were collected on electromechanical impulse counters, a printing counter, and a cumulative recorder. Overhead houselights were on $24 \mathrm{~h} /$ day.

\section{Procedure}

Max was food deprived for 2 days, and leverpressing was shaped by reinforcement of successive approximations. The animals were then placed on a schedule where one session 
was run every hour around the clock, with the two animals alternating. Each session consisted of two blocks of four schedule components, each associated with a different color of the in-line display unit. If the response requirement in a given component was not completed within $5 \mathrm{~min}$, the next component was automatically presented. White noise came on at the start of each component. If the response requirement was completed before the 5-min time limit, the noise and the stimulus light went off until $5 \mathrm{~min}$ had elapsed from the start of the component, and the next scheduled component was begun. Twelve different pseudorandom component sequences were used, and their order of presentation was changed on the average of once a week. Initially, 20 responses were required for pellet presentation, regardless of the color of the stimulus. After 7 days, response requirements of $1,20,60$, and 180 were instituted. Colors associated with the different requirements (FRs) were, from low to high, yellow, red, blue, and white for Pete, and white, blue, red, and yellow for Max. Data recorded for each component included the time to the first response, the time from the first to the last response in the component, and the total number of components completed.

The supplementary feeding experiment began 90 days after the final contingencies had been established. Free (i.e., independent of behavior) food pellets were delivered at the same time each morning, between two sessions. Thus, Pete received his free pellets at $1000 \mathrm{~h}$ between his $0900 \mathrm{~h}$ and $1100 \mathrm{~h}$ sessions, and Max received his free pellets at $1100 \mathrm{~h}$, between his $1000 \mathrm{~h}$ and $1200 \mathrm{~h}$ sessions. The pellets were automatically delivered at $20-\mathrm{sec}$ intervals. Fruit supplements were given at about the same time as the supplementary pellets. The number of pellets delivered was manipulated in an ascending series, as follows: $20,40,60,90,120,150,180$ (Pete only). The number of days each value was in effect was, respectively, $14,20,34,15,26,22$, and 16. Following the highest freepellet condition, the animals were returned to the zero-pellet baseline.

\section{RESULTS}

The overall results of the supplementary feeding manipulations are presented first, followed by a breakdown of the data within the 24-h daily cycle. All data presented were taken from the final 5 days in a particular experimental condition. Figure 1 shows the total number of components for each FR value in which responding was initiated on the final 5 days of

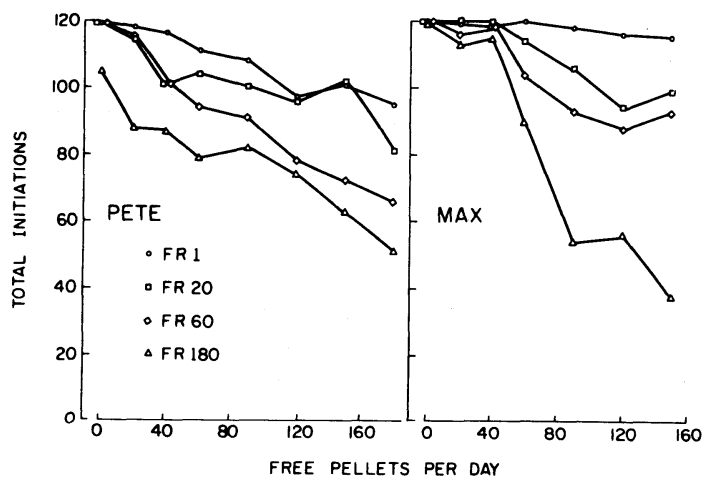

Figure 1. Total number of components of each FR value for the final 5 days of each condition in which at least one response occurred, as a function of the number of supplementary pellets given each day.

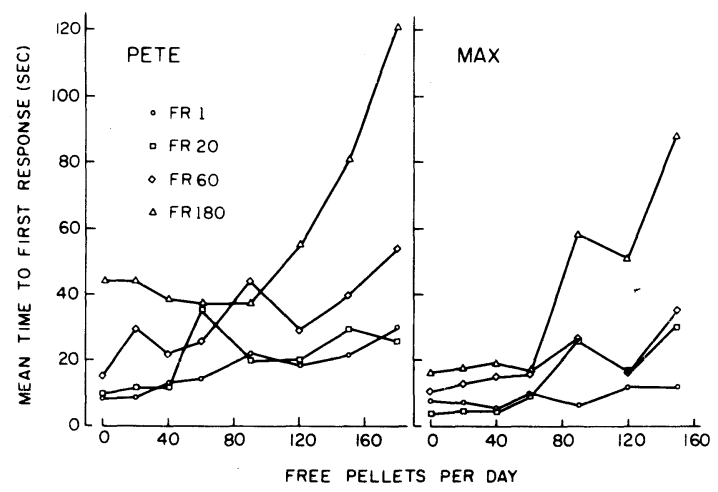

Figure 2. Mean time over 5 days to the first response in those components in which at least one response occurred, as a function of the number of supplementary pellets given each day.

each condition. Initiated components were defined as those in which at least one response occurred. The maximum possible number of initiations was 120 for 5 days, indicating that the animal responded in that component at every opportunity. Both animals showed a decrease in number of initiated components as the number of free pellets was increased. This decrease was more uniform across the FR sizes for Pete than for Max, but both animals showed a greater decrease at the high-response requirements than the low ones.

The second effect of increasing the amount of free food given each day, shown in Figure 2, was an increase in the mean time to the first response in a component. In computing these means, components in which no responding occurred were excluded. Again, as with total initiations, all components showed an effect of increasing the number of free pellets. The magnitude of the increase was not systematically related to the FR size. The time to the first response in all components increased by a factor of about 3 to 5 times the baseline as the number of free pellets increased. The FR 1 component for Max was the only exception, showing an increase of only 1.6 times the baseline value.

Response rate from the first response to the end of the ratio remained constant across both ratio size and free-pellet manipulations.

Perhaps the greatest differential effect between the components occurred in terms of failure to complete ratios that were initiated. Figure 3 shows the percentage of components initiated that were also completed. When a small number of free pellets were given, both animals completed at least $90 \%$ of the ratios they initiated regardless of the ratio size. As the number of free pellets increased, the percentage of FR 180 trials completed began to decrease. When 180 free pellets per day were given, Pete completed almost none of the FR 180s he initiated, while still completing more than $85 \%$ of shorter ratios that were initiated. Typically, when an animal initiated a ratio but did not complete it, he quit responding after fewer than 10 responses. 


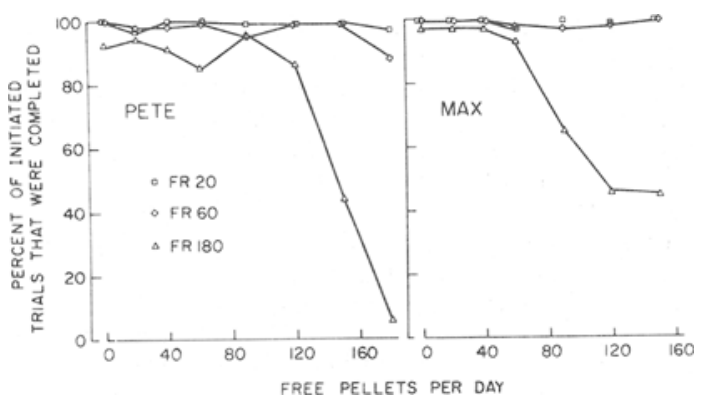

Figure 3. Percentage of completed ratios in components in which at least one response occurred.

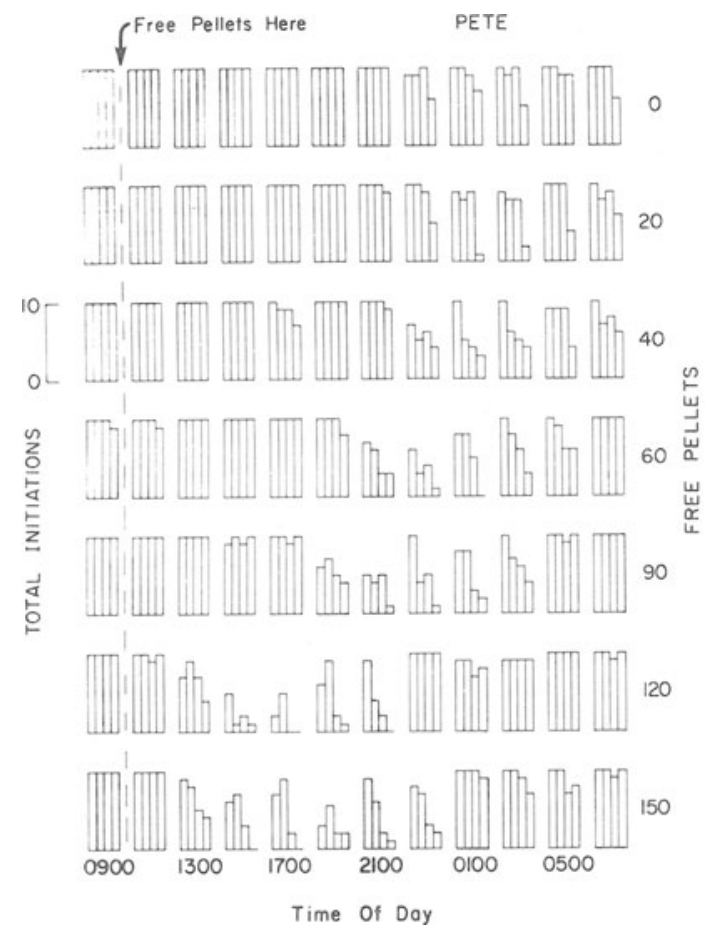

Figure 4. Total number of components for Pete in which at least one response occurred, as a function of FR size, number of free pellets given each day, and time of day. In each small fourbar histogram, the bars, from left to right, represent the FR 1, FR 20, FR 60, and FR 180 conditions. Each row represents a different deprivation condition, and each column represents a different time of day.

Daily observations were made to determine if the animals were eating all the pellets they earned or were given. Both animals continued to eat all the pellets that were available until 150 free pellets per day were given. At this value, Max failed to eat all of his free pellets, leaving them in the food tray. At 180 free pellets per day, Pete began dropping pellets into his waste pan.

To summarize, the data, averaged across the entire day, show little differential performance at the lowest number of supplementary pellets, except perhaps in terms of time to the first response. As the number of supplementary pellets was increased, differences between the components emerged, particularly with respect to component initiation and percent of initiated components completed. Similar effects were also observed within the day. Figure 4 shows total initiations for each FR value during each session of the day under all deprivation conditions except the 180-free-pellet condition for Pete. Most importantly, differential performance between the components of the multiple schedule waxes and wanes. For example, given any one of the feeding conditions, Pete showed no differential tendency to initiate responding during the $0900 \mathrm{~h}$ session, responding in all components at every opportunity. At some later time in the day, a higher number of initiations of the short FRs than of the longer FRs occurred. A similar effect was also apparent for Max, however, the temporal locus of the effect was different. When a large number of free pellets were given, Max responded at every opportunity between midnight and $0200 \mathrm{~h}$ and showed more differential performance at other hours of the day.

\section{DISCUSSION}

The present experiment demonstrated that performance in a four-component multiple-FR schedule is sensitive to both supplementary feeding and time of day. For both monkeys, the effects of either variable were greatest upon responding in the components requiring more responses. These results confirm and extend those of Carlton (1961), who showed that changes in the duration of water deprivation produced greater effects on behavior maintained by several different schedules of intermittent water reinforcement than on behavior maintained by continuous water reinforcement. Moran (1975) has questioned the traditional use of extreme states of deprivation, and the present data and those of Carlton support his position, since differential performance between components appears to be magnified by decreasing deprivation.

Nevin (1974, Note 1) has presented numerous examples where the general term "response strength" appears useful in the description of the effects of response-rate-reducing variables upon multiple and concurrent performance where interval schedules maintain responding in the various components. The present experiment and an earlier one (Elsmore, 1971) extend these results to ratio-type schedules. In a trial-based procedure, Elsmore (1971) showed that when different key colors were associated with different probabilities of reinforcement, pigeons' tendencies to peck the various colors could be modulated either by increasing the force required to operate the key or by increasing the FR required for trial completion. This is termed the "work effect" by Blough (1966), who reviewed a number of studies suggesting that the sensitivity of various psychophysical procedures may be modulated by the effort required to respond. Thus, supplementary feeding, time of day, and effort all appear to have qualitatively similar effects on behavior maintained under multiple-FR schedules. It is important that future studies explore further the range of variables producing comparable effects on multiple-FR performances, as well as isolating the specific aspects of the FR schedule (e.g., number of responses, reinforcements per hour) that are correlated with response strength. Similarity of the present results to those reported by Nevin (1974) on reinforcement 
frequency in interval schedules suggests, however, that it is frequency of reinforcement rather than number of responses that is important.

Viewed within this context, the effect of the supplementary feedings given in this experiment was to decrease the probability of responses maintained at low strength through correlation with the unfavorable conditions of reinforcement supplied by large FR schedules.

\section{REFERENCE NOTE}

1. Nevin, J. A. Response strength and reinforcement value as resistance to change. Paper presented at the meeting of the Midwestern Association of Behavior Analysis, Chicago, 1977.

\section{REFERENCES}

Blough, D. S. The study of animal sensory processes by operant methods. In W. K. Honig (Ed.), Operant behavior: Areas of research and application. New York: Appleton-CenturyCrofts, 1966.

Carlton, P. L. The interacting effects of deprivation and reinforcement schedule. Journal of the Experimental Analysis of Behavior, 1961, 4, 379-381.

Dinsmoor, J. A. The effect of hunger on discriminated responding. Joumal of Abnormal and Social Psychology, 1952, 47. 67-72.

Elsmore, T. F. Effects of response effort on discrimination performance. Psychological Record, 1971, 21, 17-24.

Ferster, C. B., \& Skinner, B. F. Schedules of reinforcement. New York: Appleton-Century-Crofts, 1957.

Gollub, L. R., \& Urban, J. T. The accentuation of a rate difference during extinction. Journal of the Experimental Analysis of Behavior. 1958, 1, 365-369.

HegGe, F. W. Auditory intensity discrimination behavior as a function of food deprivation and discrimination difficulty. Unpublished doctoral dissertation, Brown University, 1966. Moran, G. Severe food deprivation: Some thoughts regarding its exclusive use. Psychological Bulletin, 1975, 82, 543-557.

Nevin, J. A. Response strength in multiple schedules. Journal of the Experimental Analysis of Behavior, 1974, 21, 389-408.

Powell, R. W. Evidence of interaction between deprivation effects and stimulus control. Journal of the Experimental Analysis of Behavior, 1971, 16, 95-104.

Powell, R. W. Effects of stimulus control and deprivation upon discriminative responding. Journal of the Experimental Analysis of Behavior, 1973, 19, 351-360.

(Received for publication February 23, 1979.) 